\title{
Ambra1 inhibits paclitaxel-induced apoptosis in breast cancer cells by modulating the Bim/mitochondrial pathway
}

\author{
W.-L. SUN*, L. WANG, J. LUO, H.-W. ZHU, Z.-W. CAI* \\ Department of Medical Oncology, The Second Affiliated Hospital of Guangxi Medical University, Nanning, Guangxi, China \\ *Correspondence: swl20022001@hotmail.com,czw001967@sohu.com
}

Received July 10, 2018 / Accepted November 14, 2018

\begin{abstract}
Cancer cells often evade apoptosis induced by anti-cancer drugs, thereby reducing their efficacy. Autophagy/Beclin 1 regulator 1 (Ambra1) is a crucial pro-autophagic protein. It also plays an important role in the execution of apoptosis. However, the mechanism by which Ambral regulates apoptosis has not been fully clarified. Moreover, whether Ambra1 participates in the regulation of paclitaxel-induced apoptosis in breast cancer cells is not clear. Herein, we show that Ambra1 inhibits paclitaxel-induced apoptosis in breast cancer cells. Moreover, Bim and mitochondria are key effectors of Ambra1 in this process. Thus, Ambral is a protein that makes breast cancer cells resistant to apoptosis by modulating the Bim/ mitochondrial pathway and may therefore be a potential target for the breast cancer treatment.
\end{abstract}

Key words: Ambra1, Bim, apoptosis, paclitaxel, breast cancer

Breast cancer is the most common malignancy in women worldwide and is one of the leading causes of cancer-related deaths [1]. As an effective drug against breast cancer, paclitaxel (PTX) kills cancer cells mainly by inducing apoptosis $[2,3]$. However, escape from apoptosis is a hallmark of cancer cells, which reduces the effectiveness of the drug [4, 5]. Autophagy/Beclin 1 regulator 1 (Ambra1) is an essential protein upstream of the autophagic pathway; it is also an important factor in the execution of apoptosis [6-12]. In vivo, functional deficiency of Ambral causes excessive apoptotic cell death in mouse embryos [6]. In vitro, the down-regulation of Ambral enhances the sensitivity of cells to apoptotic stimuli in several cell lines, and its overexpression inhibits apoptosis [11, 12]. Therefore, Ambra1 may protect cells from apoptosis. The relationship between Ambral and autophagy and apoptosis has been comprehensively reviewed [13-16]. In fact, the dynamic interaction with anti-apoptotic protein $\mathrm{Bcl} 2$ is an important mechanism through which Ambral is thought to regulate autophagy and apoptosis [10]. In addition, in the process of apoptosis, Ambral is degraded by apoptotic proteins, which destroys its autophagic function and promotes apoptosis [11]. However, the C-terminal fragment of Ambra1, which is formed by cleavage by caspases, plays a pro-apoptotic role by inhibiting $\mathrm{Bcl} 2$ [17]. Therefore, the mechanism through which Ambral regulates apoptosis is complex and has not yet been fully elucidated. Moreover, whether Ambral is involved in PTX-induced apoptosis of breast cancer cells is also not clear.

In this work, we explored the role of Ambral in PTX-induced apoptosis in MDA-MB-231, SK-Br-3 and MCF-7 breast cancer cells, as well as the relationship between Ambral and Bim, a pro-apoptotic protein belonging to the BH3-only group of Bcl-2 family members [18-21], in regulating apoptosis. We found that down-regulation of Ambral activates the mitochondrial apoptosis pathway by increasing the expression of Bim, thereby enhancing PTX-induced apoptosis in breast cancer cells. To summarize, we propose a model in which Ambral modulates PTX-induced apoptosis of breast cancer cells by regulating the Bim/mitochondrial pathway. In addition, our findings suggest that Ambra1 may be a potential target for treatment of breast cancer.

\section{Materials and methods}

Cell lines. MCF-7, MDA-MB-231 and SK-Br-3 cells were obtained from the cell bank of Chinese Academy of Sciences (Shanghai, China). MCF-7 and SK-Br-3 cells were cultured in MEM media (Thermo Fisher, Waltham, MA, USA) and MDA-MB-231 cells were cultured in L15 media (Thermo Fisher, Waltham, MA, USA), supplemented with $10 \%$ fetal calf serum (Thermo Fisher, Waltham, MA, USA), 
$100 \mathrm{units} / \mathrm{ml}$ penicillin and $100 \mu \mathrm{g} / \mathrm{ml}$ streptomycin at $37^{\circ} \mathrm{C}$ in a humidified incubator with $5 \% \mathrm{CO}_{2}$. Before the study, the cells were passaged for 6 generations. The identity of the cell lines was determined by short tandem repeats (STR) profiling.

Assay kits and antibodies. PTX was from Hospira Australia Pty Ltd. (Victoria, Australia). The annexin V-FITC/ PI apoptosis assay kit was from Nanjing KeyGen Biotech. Co., Ltd. (Nanjing, China). The caspase-9 activity assay kit and cell counting kit-8 (CCK-8) were from the Beyotime Institute of Biotechnology (Shanghai, China). Anti-Ambra1 antibody was from Santa Cruz Biotechnology, Inc. (Santa Cruz, USA). Anti-GAPDH antibody was from MultiSciences (Lianke) Biotech Co., Ltd. (Shanghai, China). Anti-Bim and anti-cytochrome $c$ (cyt c) antibodies were from CST (Danvers, USA).

Cell viability assay. For the cell viability assay, cells were seeded at $8 \times 10^{3}$ cells per well in 96 -well flat-bottomed plates and were allowed to attach overnight at $37^{\circ} \mathrm{C}$. Afterwards, medium containing the assay agents was added to each well and cells were further cultured at $37^{\circ} \mathrm{C}$ for the indicated times. The number of viable cells was estimated by CCK-8 assay. The absorbance was measured at $450 \mathrm{~nm}$ with a microplate reader.

Apoptosis assay. For the apoptosis assay, cells were seeded at $5 \times 10^{5}$ cells in $12.5 \mathrm{~cm}^{2}$ tissue culture flasks and were treated as described for the CCK- 8 assay for the indicated times. Afterward, cells were trypsinized at the indicated time and dyed with annexin V-FITC and PI according to the manufacturer's instructions. Then, apoptotic cells were detected with a flow cytometer.

Caspase-9 activity assay. Cells were collected after treatment with the assay agents for the indicated time, and $30 \mu \mathrm{l}$ of lysis buffer was added to the collected cells. The cells were resuspended in the lysis buffer and incubated on ice with light agitation for $30 \mathrm{~min}$. Lysates were centrifuged at $13000 \mathrm{rpm}$ for $5 \mathrm{~min} ; 10 \mu \mathrm{l}$ of supernatant was used to assay the protein concentration with Bradford reagent, and another $10 \mu \mathrm{l}$ was used to assay caspase- 9 activity. The activity of caspase- 9 was assayed with Ac-LEHD-pNA as a substrate; the samples were incubated at $37^{\circ} \mathrm{C}$ for $2 \mathrm{~h}$, and $\mathrm{OD}$ values were detected at $405 \mathrm{~nm}$ with a microplate reader.

Western blotting. For western blotting analyses, cells were seeded in $25-\mathrm{cm}^{2}$ tissue culture flasks and were allowed to reach approximately $80 \%$ confluency in fresh medium before treatment with the agents. After treatment, detached and attached cells were collected by centrifugation, and whole-cell lysates were obtained using a lysis buffer $(1 \times \mathrm{PBS} \mathrm{pH} 7.6,1 \% \mathrm{NP}-40,0.1 \%$ sodium dodecyl sulfate and $0.5 \%$ sodium deoxycholate supplemented with inhibitor cocktails). Approximately 30-50 $\mu \mathrm{g}$ of total protein from each group was electrophoretically separated on 12 or $15 \%$ SDS-PAGE gels and electrotransferred to polyvinylidene fluoride membranes (PVDF membranes, Pierce). The PVDF membranes were blocked with $5 \%$ nonfat dry milk in Tris- buffered saline-Tween 20 (TBST, pH7.6) for $1 \mathrm{~h}$ at room temperature, incubated with the primary antibodies diluted in 5\% nonfat dry milk in TBST with light agitation overnight at $4{ }^{\circ} \mathrm{C}$, washed with TBST three times, and incubated with the secondary antibodies diluted in 5\% nonfat dry milk in TBST with light agitation for $1 \mathrm{~h}$ at room temperature; the proteins were then detected with electrochemiluminescence (Bio-Rad, California, USA).

Lentiviral vector and siRNA construction and transfection. A lentiviral vector- $A M B R A 1$ transfected with fulllength human AMBRA1 cDNA (abbreviated as OE) and an empty vector (Empty, as a control) were constructed by Genechem (Shanghai, China).Two target-specific AMBRA1 siRNAs (si \#1 and si \#2), a target-specific BIM siRNA and control scrambled siRNA were synthesized by GenePharma (Shanghai, China). The sequence of the si \#1 was GCT GGA ATC TTC CCT CAT TTC, the sequence of si \#2 was GGA GAC ATG TCA GTA TCA ACT, and the sequence of si-BIM was GAC CGA GAA GGU AGA CAA UUG (21). The siRNAs were transfected into cells by Lipofectamine ${ }^{\mathrm{TM}}$ 2000 (Invitrogen, California, USA); the transfection was performed according to the instructions of the manufacturer.

Colony-formation assay. Cells were seeded at $8 \times 10^{2}$ cells per well in a 6-well plate and cultured for 16 days. Cells were washed twice with PBS and fixed in 4\% paraformaldehyde for $30 \mathrm{~min}$. Then, the cells were washed once with PBS. Colonies were stained with GIMSA for $20 \mathrm{~min}$, washed twice with ddH2O, allowed to dry, and the number of colonies was counted.

Real-time Quantitative PCR (qRT-PCR). RNA was extracted by using Trizol reagent (Generay Biotech (Shanghai) Co., Ltd., Shanghai, China) as instructed by the supplier. cDNA synthesis was generated using a reverse transcription kit (Vazyme Biotech Co., Ltd., Shanghai, China) according to the manufacturer's recommendations. cDNA from cell samples was amplified by qRT-PCR with specific primers for AMBRA1 (upper: TGGGGAGGTTAGGATTTGGGA, lower: GAGCCGTAGGGTGGAAAGC), BIM (upper: CAGACAGGAGCCCAGCACC, lower: TCCAATACGCCGCAACTCTT) and GAPDH (upper: TGACTTCAACAGCGACACCCA, lower: CACCCTGTTGCTGTAGCCAAA) with the ChamQ SYBR Color qPCR Master Mix (Vazyme Biotech Co., Ltd., Shanghai, China). The primers were synthesized by Shanghai Sunny Biotechnology (Shanghai, China) Data were normalized to GAPDH expression.

Statistical analysis. Statistical comparisons of the mean values were performed by the Student 2 -tailed t test. Data are shown as the means \pm SD of three independent experiments. Values of $\mathrm{p}<0.05$ were considered statistically significant.

\section{Results}

Down-regulation of Ambra1 enhances PTX-induced apoptosis in breast cancer cells. To investigate the role of Ambra1 in PTX-induced apoptosis in MDA-MB-231, 
SK-Br-3, and MCF-7 breast cancer cells, we examined the effect of PTX on Ambral expression. The cells were treated with $10.0 \mu \mathrm{M}$ PTX for $24 \mathrm{~h}$. Then, the mRNA and protein of Ambral were detected by qRT-PCR and western blotting, respectively. It was revealed that Ambral mRNA and protein increased after treatment with PTX (Figure 1A, ${ }^{\star} \mathrm{p}<0.05$ ). Next, we knocked down Ambral using two target-specific
AMBRA1 siRNAs (si \#1 and si \#2). An irrelevant siRNA (scramble) was used as a control. Si \#1, si \#2, and scrambled siRNA were transfected into the cells for $72 \mathrm{~h}$. Si \#1 and si \#2 significantly reduced the expression of Ambral in both protein and mRNA (Figure $1 \mathrm{~B},{ }^{\star} \mathrm{p}<0.05$ ). Upon Ambral being knocked down, the cells were treated with $10.0 \mu \mathrm{M}$ PTX for an additional $24 \mathrm{~h}$. Then, cell viability, caspase- 9 activity
A

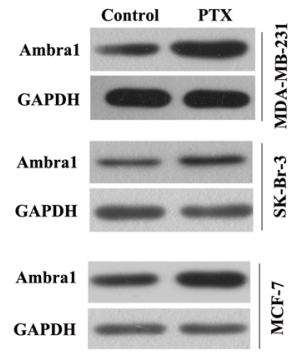

B

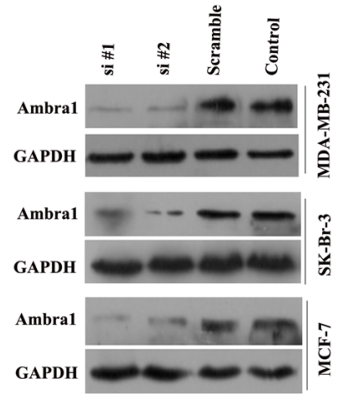

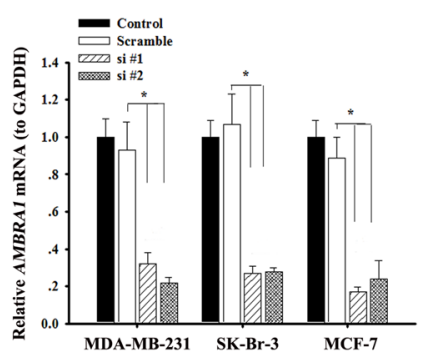

C

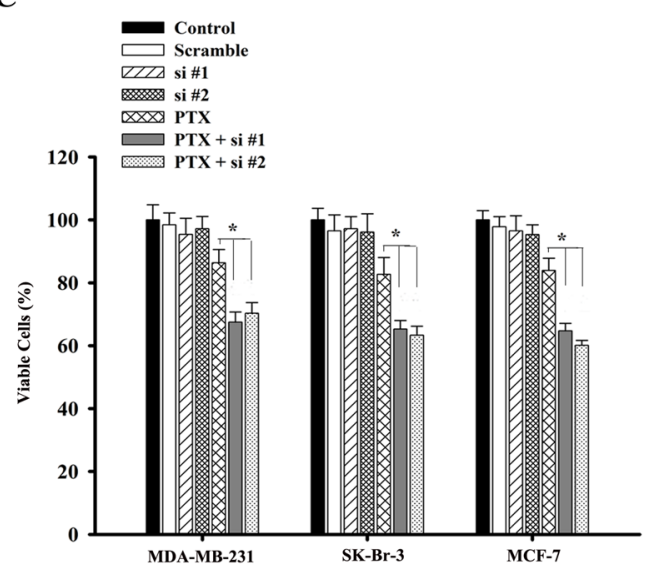

D

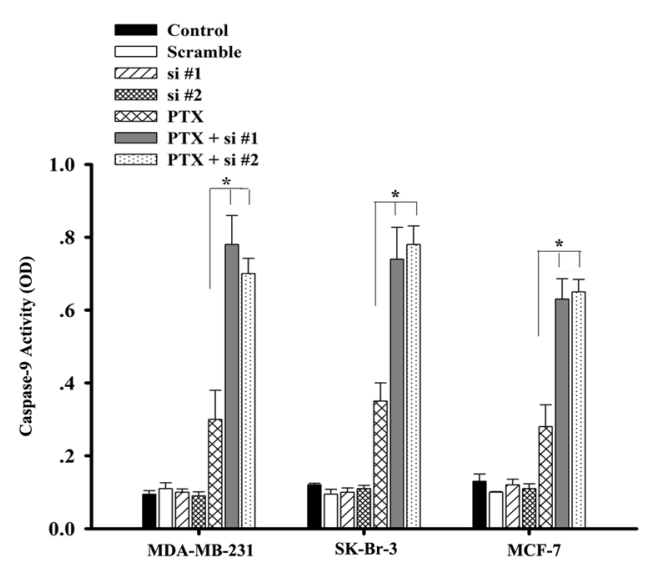

$\mathbf{E}$
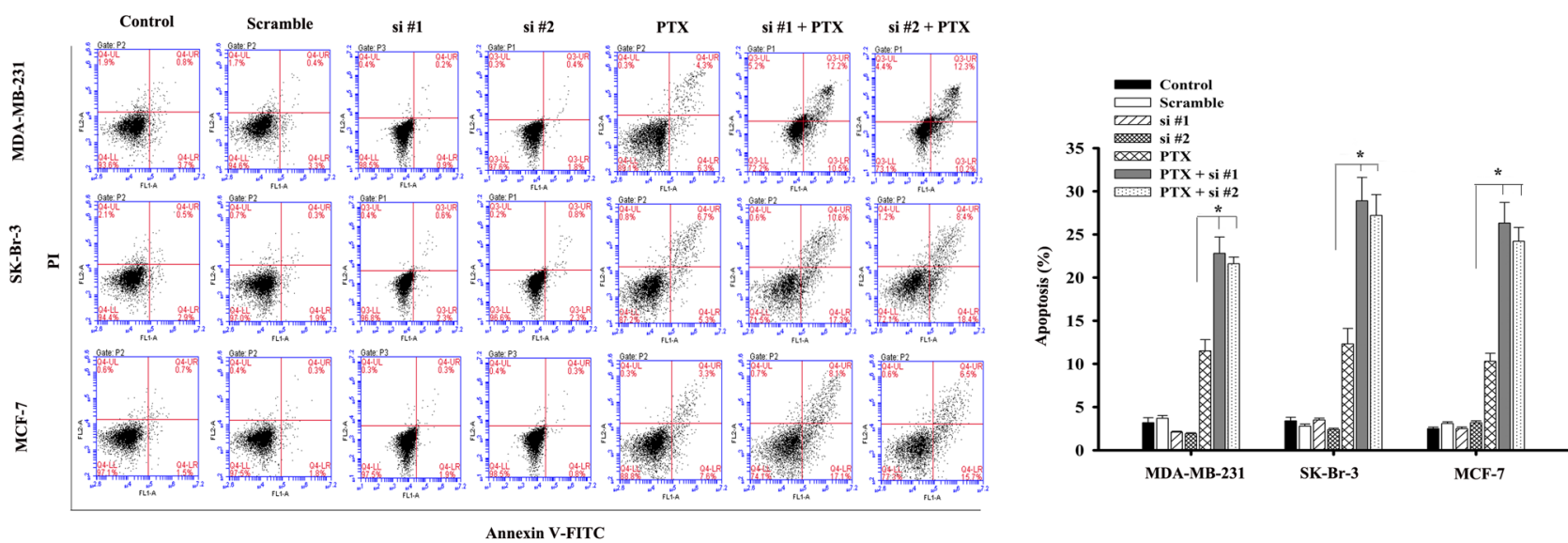

Figure 1. Knockdown of Ambra1 increases PTX-induced apoptosis in breast cancer cells. A) MCF-7, MDA-MB-231 and SK-Br-3 cells were treated by $10.0 \mu \mathrm{M}$ PTX for $24 \mathrm{~h}$; then Ambra 1 protein and mRNA were tested by western blotting and qRT-PCR, respectively. B) The cells were treated by targetspecific AMBRA1 siRNAs (si \# 1 or si \#2) and scrambled siRNA for $72 \mathrm{~h}$, and then Ambra1 was detected by western blotting. At the same time, AMBRA1 mRNA was examined by qRT-PCR. C) Cells were incubated with scrambled siRNA or si \#1 or si \#2 for $72 \mathrm{~h}$, followed by treatment with $10.0 \mu \mathrm{M}$ PTX for another $24 \mathrm{~h}$; then cell viability was analyzed by CCK-8. D) Caspase-9 activity was assayed. E) Apoptosis was determined using annexin V-FITC/PI and flow cytometry. All the results (means \pm SD) come from three independent experiments $\left({ }^{*} \mathbf{p}<0.05\right)$. 
and apoptosis were analyzed. The treatment of si \#1 or si \#2 plus PTX resulted in a significant decrease in cell viability, whereas caspase- 9 activity and apoptosis increased significantly (Figures $1 \mathrm{C}-\mathrm{E},{ }^{*} \mathrm{p}<0.05$ ). Cell viability was further confirmed by colony-formation assay (Figure $2,{ }^{*} \mathrm{p}<0.05$ ). Therefore, Ambral reduced PTX-induced apoptosis in breast cancer cells, and its down-regulation enhanced intrinsic apoptosis by activating caspase- 9 .

Ambra1 negatively regulates Bim expression. To explore the potential mechanism by which Ambral regulates PTX-induced apoptosis, we analyzed the effect of Ambral on Bim expression. Bim (also known as BCL2L11) belongs to the $\mathrm{BH} 3$-only $\mathrm{Bcl} 2$ family and is an essential protein for mitochondrial apoptosis [18-20]. First, MDA-MB-231, SK-Br-3, and MCF-7 cells were treated with si \#1, si \#2, or scrambled siRNA for $72 \mathrm{~h}$. Next, the mRNA of BIM was tested by qRT-PCR. As expected, knockdown of AMBRA1 resulted in a significant increase in BIM mRNA levels (Figure 3A, $\left.{ }^{*} \mathrm{p}<0.05\right)$. Correspondingly, Bim protein was also elevated, as determined by western blotting (Figure $3 \mathrm{~B}$ ). Thus, knockdown of Ambral promoted the expression of Bim in breast cancer cells. To further probe the effect of Ambral on Bim expression, a lentiviral vector-AMBRA1 transfected with full-length human AMBRA1 cDNA (abbreviated as OE) and an empty vector (Empty, as a control) were constructed to overexpress Ambra1 in MDA-MB-231 cells. After transfection with LV-AMBRA1 for $72 \mathrm{~h}$, the expression of Ambral was significantly increased in both mRNA and protein (Supplementary Figure $1 \mathrm{~A},{ }^{*} \mathrm{p}<0.05$ ). At the same time, the overexpression of Ambral led to a significant decrease in the expression of Bim (Supplementary Figure $1 \mathrm{~B},{ }^{\star} \mathrm{p}<0.05$ ). Therefore, Ambral negatively regulates the expression of Bim in breast cancer cells.

To determine whether Bim had a regulatory effect on Ambral expression, we knocked down Bim by si-BIM. $B I M$ mRNA and protein were significantly decreased after
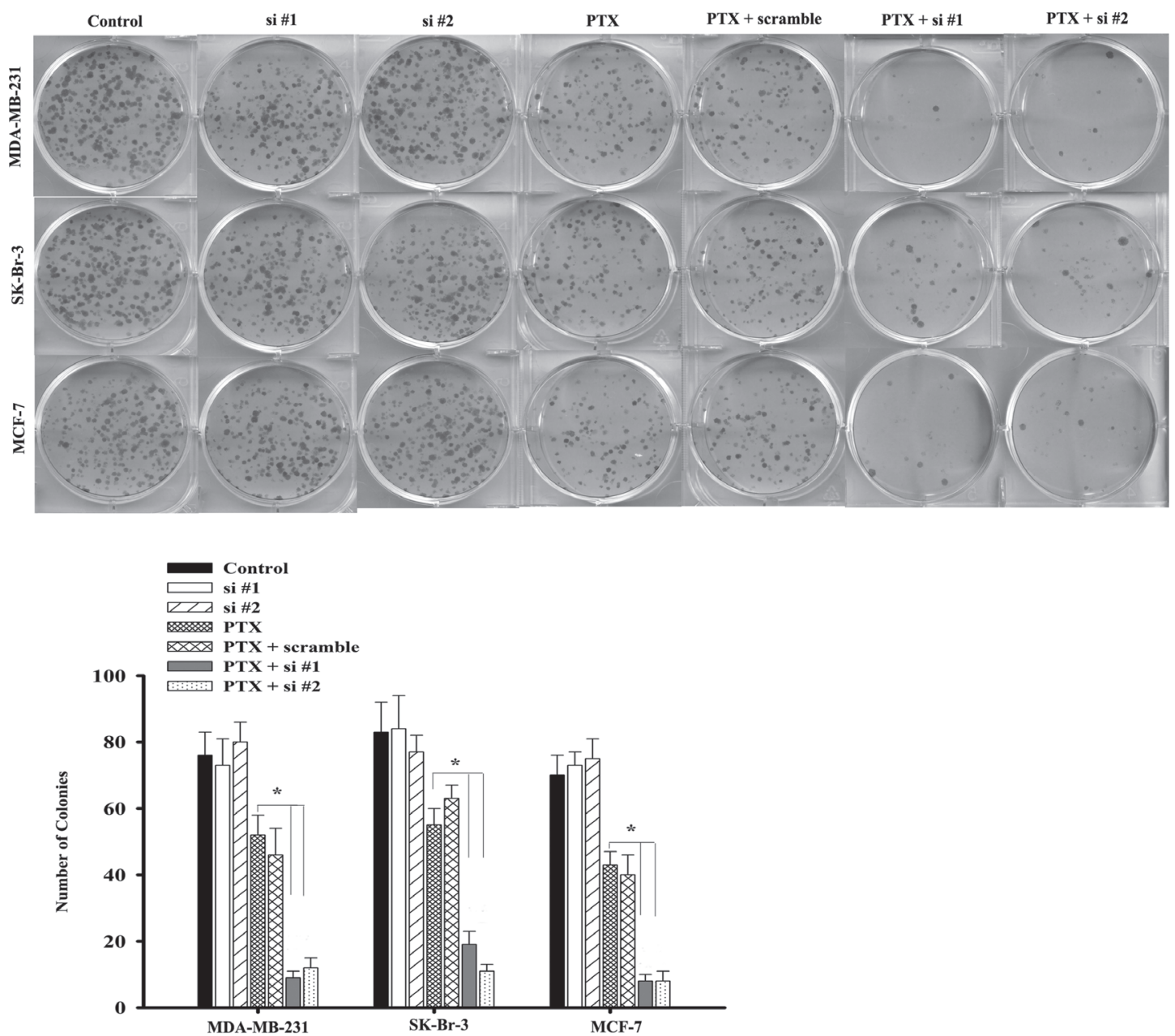

Figure 2. Knockdown of Ambra1 inhibits colony formation in breast cancer cells. MCF-7, MDA-MB-231 and SK-Br-3 cells were treated by targetspecific AMBRA1 siRNAs (si \#1 or si \#2) and scrambled siRNA for $72 \mathrm{~h}$, followed by treatment with $10.0 \mu \mathrm{M}$ PTX for another $24 \mathrm{~h}$. Then, cells were seeded in 6-well plate and cultured for 16 days, and the number of colonies was counted. All the data (means \pm SD) are from three independent experiments $\left({ }^{*} \mathbf{p}<0.05\right)$. 
A

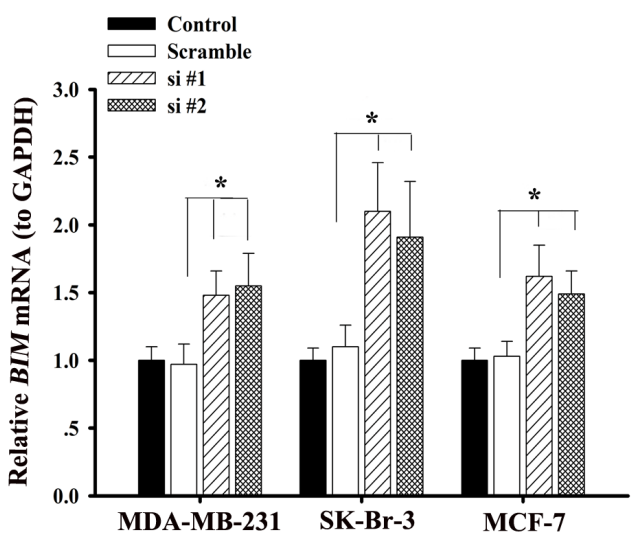

B

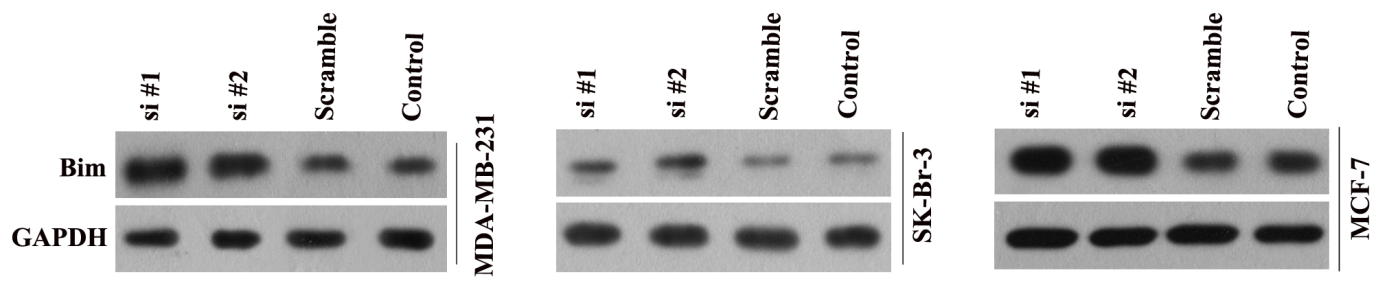

C

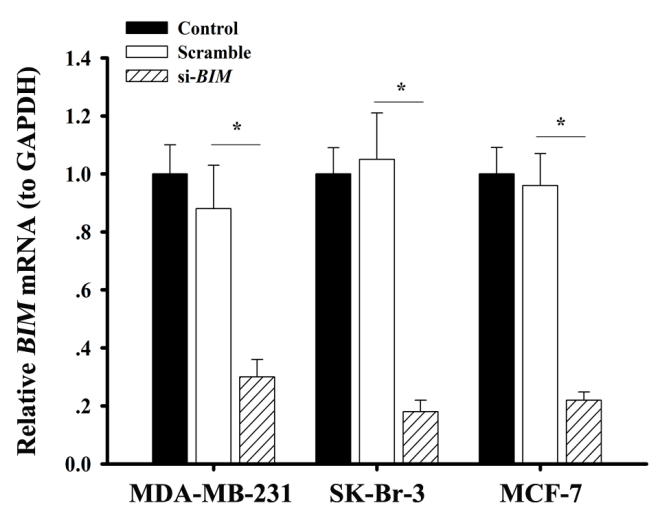

D

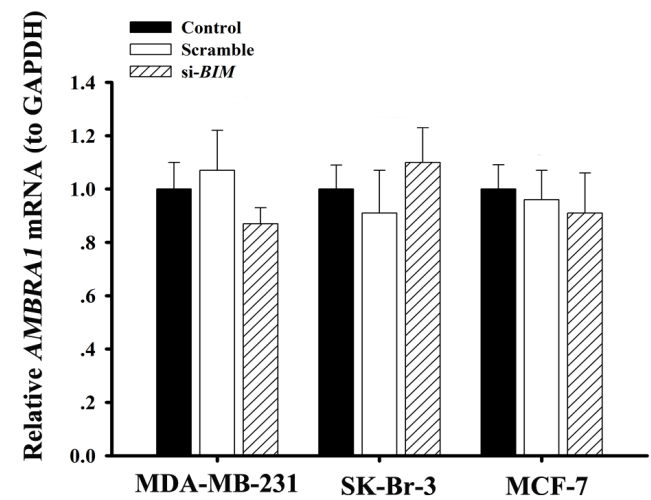

$\mathbf{E}$

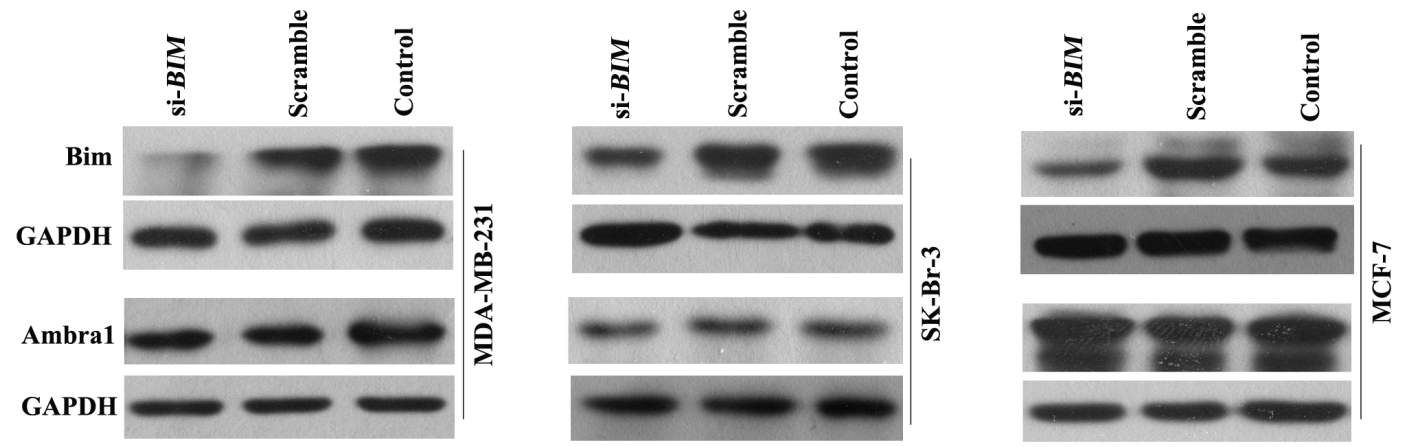

Figure 3. Ambral negatively regulates Bim expression. Cells were transfected with scrambled siRNA or si \#1 or si \#2 for $72 \mathrm{~h}$, the mRNA (A) and protein (B) of Bim were tested by $\mathrm{qRT}$-PCR and western blotting respectively. C) Cells were incubated with target-specific BIM si-BIM and scrambled siRNA for $72 \mathrm{~h}$, and then the mRNA of BIM was examined by qRT-PCR; AMBRA1 mRNA was detected concurrently (D). Then, the proteins of Bim and Ambral were analyzed by western blotting $(\mathrm{E})$. All the data (means $\pm \mathrm{SD})$ come from three independent experiments $\left({ }^{*} \mathrm{p}<0.05\right)$. 
transfection with si-BIM for $72 \mathrm{~h}$ (Figure $3 \mathrm{C}$ and upper panel of $\left.3 \mathrm{E},{ }^{*} \mathrm{p}<0.05\right)$. However, there was no significant change in the mRNA and protein of Ambral (Figure 3D and lower panel of $\left.3 \mathrm{E},{ }^{* *} \mathrm{p}>0.05\right)$. Therefore, there was no mutual regulation between Ambra1 and Bim.

PTX induces intrinsic apoptosis through the $\mathrm{Bim} /$ mitochondrial pathway. To confirm the role of Bim in PTX-induced apoptosis of MDA-MB-231, SK-Br-3 and MCF-7 breast cancer cells, we knocked down Bim by si-BIM. Then, the cells were treated with $10.0 \mu \mathrm{M}$ PTX for another $24 \mathrm{~h}$. Subsequently, cytochrome c (cyt c) release was detected by western blotting. The release of cyt $\mathrm{c}$ is an indicator of mitochondrial membrane potential (MMP) damage and is required for caspase- 9 activation and intrinsic apoptosis [22, 23]. The results showed that the knockdown of BIM inhibited cyt $c$ release induced by PTX treatment (Figure 4A). At the same time, the caspase- 9 activity and apoptosis caused by PTX treatment also decreased significantly (Figures $4 \mathrm{~B}$ and $\left.4 \mathrm{C},{ }^{*} \mathrm{p}<0.05\right)$. Thus, PTX induces apoptosis through the Bim/ mitochondrial pathway in breast cancer cells.
Bim is required for Ambral to regulate PTX-induced apoptosis. To confirm whether Bim was involved in the regulation of apoptosis by Ambral, we knocked down Bim and Ambral concurrently. MDA-MB-231 cells were incubated with scrambled siRNA, si \#1, si-BIM or si \#1 combined with si-BIM for $72 \mathrm{~h}$. The combination of si\# 1 and si-BIM reduced the mRNA and protein levels of both Ambral and Bim simultaneously (Figures $5 \mathrm{~A}$ and $5 \mathrm{~B},{ }^{*} \mathrm{p}<0.05$ ). Next, the cells that were transfected with scrambled siRNA, si $\# 1$, si-BIM, or si \#1 combined with si-BIM were treated with PTX for additional $24 \mathrm{~h}$, and cyt $\mathrm{c}$ release was tested by western blotting. The increase of cyt $c$ release caused by PTX or PTX plus si \#1 was inhibited by si-BIM with or without si \#1 (Figure 5C). In addition, si-BIM alone or in combination with si \#1 had a similar effect on cyt c release (Figure 5C). In fact, the similar effect also occurred in the regulation of caspase- 9 activity and apoptosis by si-BIM alone or in combination with si \#1 (Figure 5D, ${ }^{*} \mathrm{p}<0.05$ ). Therefore, Bim is required for Ambral to regulate PTX-induced apoptosis in breast cancer cells.

\section{A}

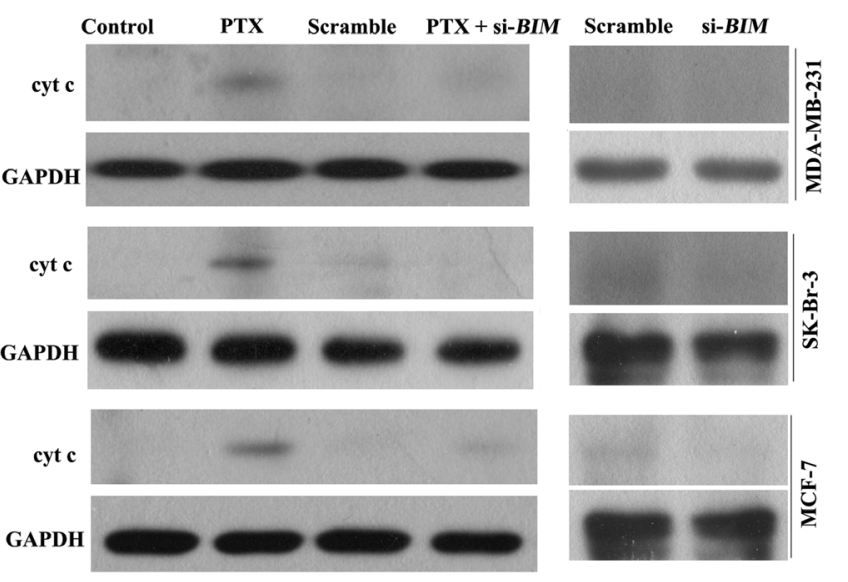

B

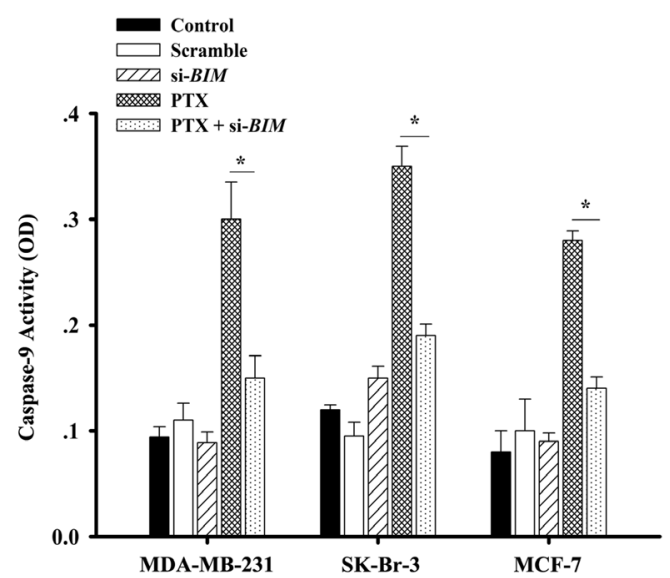

C

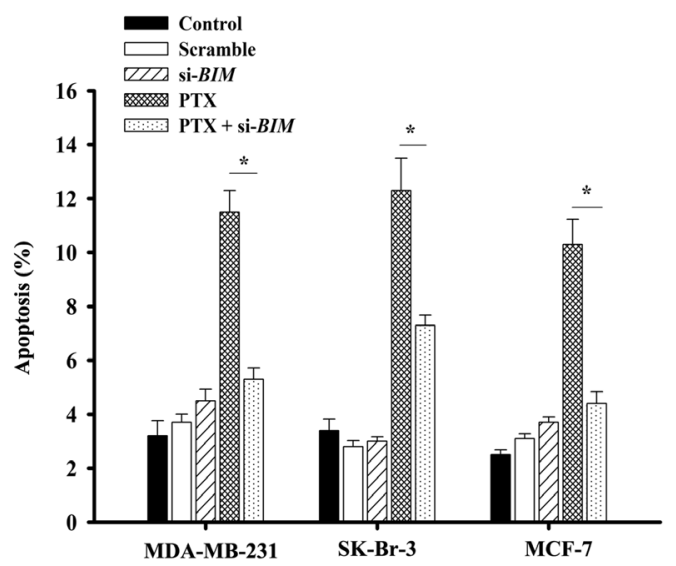

Figure 4. PTX induces intrinsic apoptosis via the Bim/mitochondrial pathway. A) Cells were incubated with scrambled siRNA or si-BIM for $72 \mathrm{~h}$, followed by treatment with $10.0 \mu \mathrm{M}$ PTX for another $24 \mathrm{~h}$; then cyt c was detected by western blotting. B) Caspase-9 activity and C) apoptosis were assayed respectively. All the data (means $\pm \mathrm{SD}$ ) are from three independent experiments $\left({ }^{*} \mathbf{p}<0.05\right)$. 
A

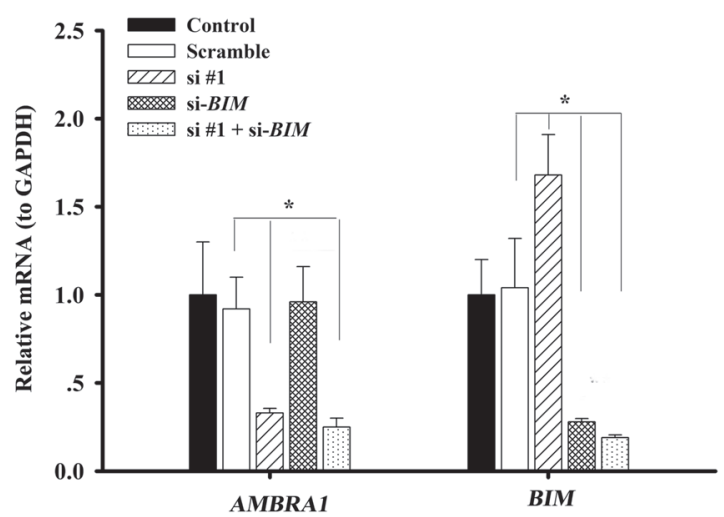

B

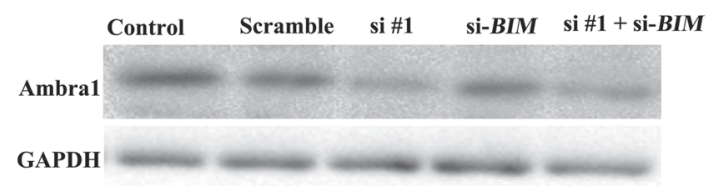

Bim

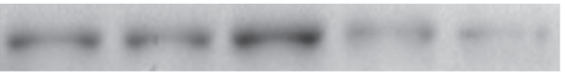

GAPDH

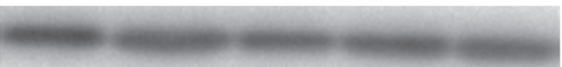

C

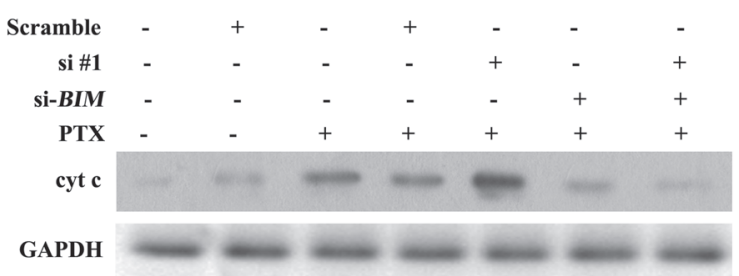

D
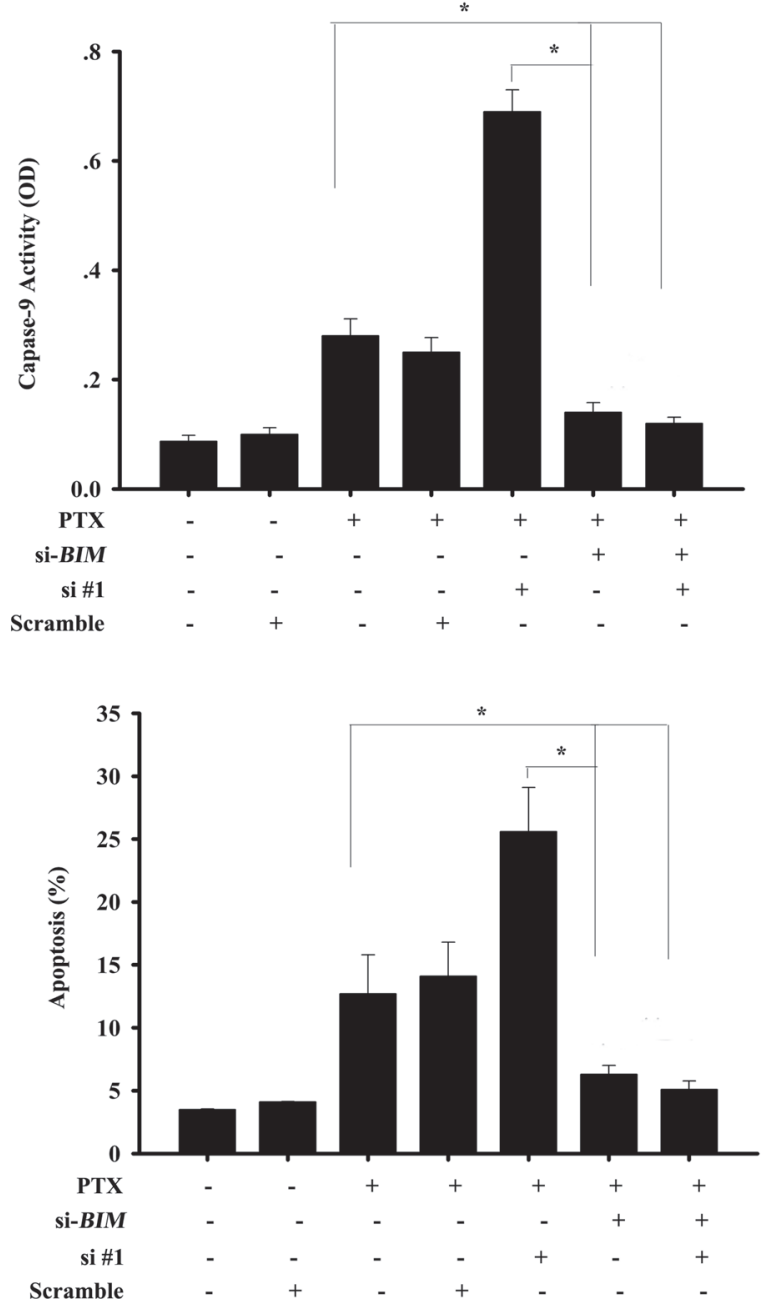

Figure 5. Bim is required for Ambral to regulate PTX-induced apoptosis. A) MDA-MB-231 cells were transfected with scrambled siRNA, si \#1, si-BIM or si \#1 combined with si-BIM for $72 \mathrm{~h}$; the mRNA of BIM and AMBRA1 were tested by qRT-PCR, and B) the proteins of Bim and Ambral were detected by western blotting. C) Cells were incubated with scrambled siRNA, si \#1, si-BIM, or si \#1 combined with si-BIM for 72 h, followed by treatment with $10.0 \mu \mathrm{M}$ PTX for another $24 \mathrm{~h}$. Then cyt c was detected by western blotting, and D) caspase-9 activity and apoptosis were assayed respectively. All the data (means \pm SD) are from three independent experiments $\left({ }^{*} p<0.05\right)$.

\section{Discussion}

Our results indicate that Ambral inhibits PTX-induced apoptosis in breast cancer cells and that Bim is a crucial protein in this process. Based on our results, we propose a model in which Ambral modifies PTX-induced apoptosis of breast cancer cells by modulating the Bim/mitochondrial pathway.

As mentioned above, Ambra1, a key factor in the autophagic pathway, is also closely related to apoptosis. Indeed, there is a complex crosstalk between autophagy and apoptosis [24]. Usually, numerous autophagic proteins are involved in apoptosis regulation and vice versa. Ambral is one of the key proteins in this crosstalk [15]. It regulates autophagy and apoptosis mainly through dynamic binding to $\mathrm{Bcl} 2$ [10]. Normally, Ambra1 preferentially binds to the mitochondria-resident $\mathrm{Bcl} 2$ to block autophagy. The mitochondriaresident $\mathrm{Bcl} 2$ exerts an anti-apoptotic function [25]. Upon the autophagy initiation, Ambral is released from Bcl-2 and combines with Beclin1 to promote autophagy [6]. Interestingly, the combination of Ambral and mitochondria-resident $\mathrm{Bcl} 2$ is also disturbed by apoptosis [10]. Thus, Ambral has a dual function both in autophagy and cell death control. Pagliarini et al. has demonstrated that Ambral is rapidly degraded by caspases and calpains during apoptosis, which destroys its pro-autophagic function and promotes apoptosis [11]. Therefore, Ambral is a protective protein. In line with the above results, we found that down-regulation of Ambra1 
enhanced PTX-induced intrinsic apoptosis by activating caspase- 9 in breast cancer cells. Thus, Ambral makes the cells resistant to PTX-induced apoptosis. However, Strappazzon et al. found that the C-terminal part of Ambra1, generated by caspases-mediated cleavage, acts as a positive mediator for mitochondrial apoptosis by inactivating the anti-apoptotic factor $\mathrm{Bcl} 2$ [17]. This suggests that the effect of Ambra1 on apoptosis depends on whether the full-length or cleaved form of the protein is present.

Up to now, the mechanism by which Ambral regulates apoptosis has not been fully clarified. Bim belongs to the pro-apoptotic group of the $\mathrm{Bcl} 2$ family and is a key protein in mitochondrial apoptosis [18-20]. Thus, we decided to explore the relationship between Ambral and Bim in PTX-induced apoptosis. Our results show that down-regulation of Ambral brought about an increase in Bim expression, which was parallel to the increase of PTX-induced apoptosis; whereas up-regulation of Ambral expression had opposite effect. In turn, Bim did not significantly modify Ambra1 expression. Therefore, Ambral negatively regulates Bim expression in breast cancer cells. In fact, Bim was required for PTX to induce mitochondrial apoptosis in breast cancer cells, because its down-regulation inhibited release of the cyt c, caspase- 9 activity and apoptosis caused by the drug. Furthermore, the down-regulation of Bim also inhibited increased PTX-induced apoptosis caused by Ambral knockdown. A similar effect was achieved when Ambral and Bim were knocked-down simultaneously. Therefore, Bim is required for Ambral to regulate PTX-induced apoptosis in breast cancer cells.

In summary, Ambral is involved in the regulation of PTX-induced apoptosis in breast cancer cells. In this process, Bim and the mitochondrial apoptotic pathway are crucial effectors of Ambra1. Therefore, we propose a novel model of Ambral in the regulation of PTX-induced apoptosis in breast cancer cells. In addition, our results also indicate that Ambra1 may be a potential target for the treatment of breast cancer.

Supplementary information is available in the online version of the paper.

Acknowledgements: This work was supported by the National Natural Science Foundation of China (grant number 81360340); the Natural Science Foundation of Guangxi Province (grant number 2016GXNSFAA380246) and the Wu Jieping Medical Foundation Clinical Research Special Fund (grant number 320.6750.12689).

\section{References}

[1] SIEGEL RL, MILLER KD, JEMAL A. Cancer Statistics, 2017. CA Cancer J Clin 2017; 67: 7-30. https://doi.org/10.3322/ caac. 21387

[2] NCCN clinical practice guidelines in oncology, breast cancer. Version I. 2018. Available at https://www.nccn.org/professionals/physician_gls/default.aspx
[3] WANG TH, WANG HS, SOONG YK. Paclitaxel-induced cell death: where the cell cycle and apoptosis come together. Cancer 2000; 88: 2619-2628.

[4] HANAHAN D, WEINBERG RA. Hallmarks of cancer: the next generation. Cell 2011; 144: 646-674. https://doi. org/10.1016/j.cell.2011.02.013

[5] PAN ST, LI ZL, HE ZX, QIU JX, ZHOU SF. Molecular mechanisms for tumour resistance to chemotherapy. Clin Exp Pharmacol Physiol 2016; 43: 723-737. https://doi. org/10.1111/1440-1681.12581

[6] FIMIA GM, STOYKOVA A, ROMAGNOLI A, GIUNTA L, DI BARTOLOMEO S et al. Ambral regulates autophagy and development of the nervous system. Nature 2007; 447: 1121-1125. https://doi.org/10.1038/nature05925

[7] DI BARTOLOMEO S, CORAZZARI M, NAZIO F, OLIVERIO S, LISI G et al. The dynamic interaction of AMBRA1 with the dynein motor complex regulates mammalian autophagy. J Cell Biol 2010; 191: 155-168. https://doi.org/10.1083/ jcb.201002100

[8] NAZIO F, STRAPPAZZON F, ANTONIOLI M, BIELLI P, CIANFANELLI V et al. mTOR inhibits autophagy by controlling ULK1 ubiquitination, self-association and function via AMBRA1 and TRAF6. Nat Cell Biol 2013; 4: 406-416. https://doi.org/10.1038/ncb2708

[9] ANTONIOLI M, ALBIERO F, NAZIO F, VESCOVO T, PERDOMO AB et al. AMBRA1 interplay with cullin E3 ubiquitin ligases regulates autophagy dynamics. Dev Cell 2014; 6: 734-746. https://doi.org/10.1016/j.devcel.2014.11.013

[10] STRAPPAZZON F, VIETRI-RUDAN M, CAMPELLO S, NAZIO F, FLORENZANO F et al. Mitochondrial BCL-2 inhibits AMBRA1-induced autophagy. EMBO J 2011; 30: 1195-1208. https://doi.org/10.1038/emboj.2011.49

[11] PAGLIARINI V, WIRAWAN E, ROMAGNOLI A, CICCOSANTI F, LISI G et al. Proteolysis of Ambral during apoptosis has a role in the inhibition of the autophagic pro-survival response. Cell Death Differ 2012; 19: 1495-1504. https://doi. org/10.1038/cdd.2012.27

[12] GU W, WAN DW, QIAN QY, YI B, HE Z et al. Ambra1 Is an Essential Regulator of Autophagy and Apoptosis in SW620 Cells: Pro-Survival Role of Ambra1. PLoS One 2014; 9: e90151. https://doi.org/10.1371/journal.pone.0090151

[13] CIANFANELLI V, NAZIO F, CECCONI F. Connecting autophagy: AMBRA1 and its network of regulation. Mol Cell Oncol 2015; 2: e970059. https://doi.org/10.4161/23723548.2 014.970059

[14] CIANFANELLI V, ZIO DD, BARTOLOMEO SD, NAZIO F, STRAPPAZZON F et al. Ambral at a glance. J Cell Sci 2015; 128: 2003-2008. https://doi.org/10.1242/jcs.168153

[15] FIMIA GM, CORAZZARI M, ANTONIOLI M, PIACENTINI M. Ambral at the crossroad between autophagy and cell death. Oncogene 2013; 32: 3311-3318. https://doi. org/10.1038/onc.2012.455

[16] SUN WL. Ambral in autophagy and apoptosis: Implications for cell survival and chemotherapy resistance. Oncol Let 2016; 12: 367-374. https://doi.org/10.3892/ol.2016.4644

[17] STRAPPAZZON F, DI RITA A, CIANFANELLI V, D'ORAZIO M, NAZIO F et al. Prosurvival AMBRA1 turns into a proapoptotic $\mathrm{BH} 3$-like protein during mitochondrial apoptosis. Autophagy 2016; 12: 963-975. https://doi.org/10 $.1080 / 15548627.2016 .1164359$ 
[18] PUTHALAKATH H, O'REILLY LA, GUNN P, LEE L, KELLY PN et al. ER stress triggers apoptosis by activating BH3only protein Bim. Cell 2007; 129: 1337-1349. https://doi. org/10.1016/j.cell.2007.04.027

[19] O'CONNOR L, STRASSER A, O'REILLY LA, HAUSMANN G, ADAMS JM et al. Bim: a novel member of the Bcl-2 family that promotes apoptosis. EMBO J 1998; 17: 384-395. https:// doi.org/10.1093/emboj/17.2.384

[20] SHUKLA S, SAXENA S, SINGH BK, KAKKAR P. BH3only protein BIM: An emerging target in chemotherapy. Eur J Cell Biol 2017; 96: 728-738. https://doi.org/10.1016/j. ejcb.2017.09.002

[21] LUO S, GARCIA-ARENCIBIA M, ZHAO R, PURI C, $\mathrm{TOH} P \mathrm{P}$ et al. Bim inhibits autophagy by recruiting Beclin 1 to microtubules. Mol Cell 2012; 47: 359-370. https://doi. org/10.1016/j.molcel.2012.05.040
[22] LI P, NIJHAWAN D, BUDIHARDJO I, SRINIVASULA SM, AHMAD $M$ et al. Cytochrome $\mathrm{c}$ and dATP-dependent formation of Apaf-1/caspase- 9 complex initiates an apoptotic protease cascade. Cell 1997; 91: 479-489. https://doi. org/10.1016/S0092-8674(00)80434-1

[23] LIU X, KIM CN, YANG J, JEMMERSON R, WANG X. Induction of apoptotic program in cell-free extracts: requirement for dATP and cytochrome c. Cell 1996; 86: 147-157. https://doi.org/10.1016/S0092-8674(00)80085-9

[24] MAIURI MC, ZALCKVAR E, KIMCHI A, KROEMER G. Self-eating and self-killing: crosstalk between autophagy and apoptosis. Nat Rev Mol Cell Biol 2007; 8: 741-752. https:// doi.org/10.1038/nrm2239

[25] LEVINE B, SINHA S, KROEMER G. Bcl-2 family members: dual regulators of apoptosis and autophagy. Autophagy 2008; 4: 600-606. https://doi.org/10.4161/auto.6260 


\section{Ambral inhibits paclitaxel-induced apoptosis in breast cancer cells by modulating the Bim/mitochondrial pathway}

W.-L. SUN, L. WANG, J. LUO, H.-W. ZHU, Z.-W. CAI

Supplemental material

A
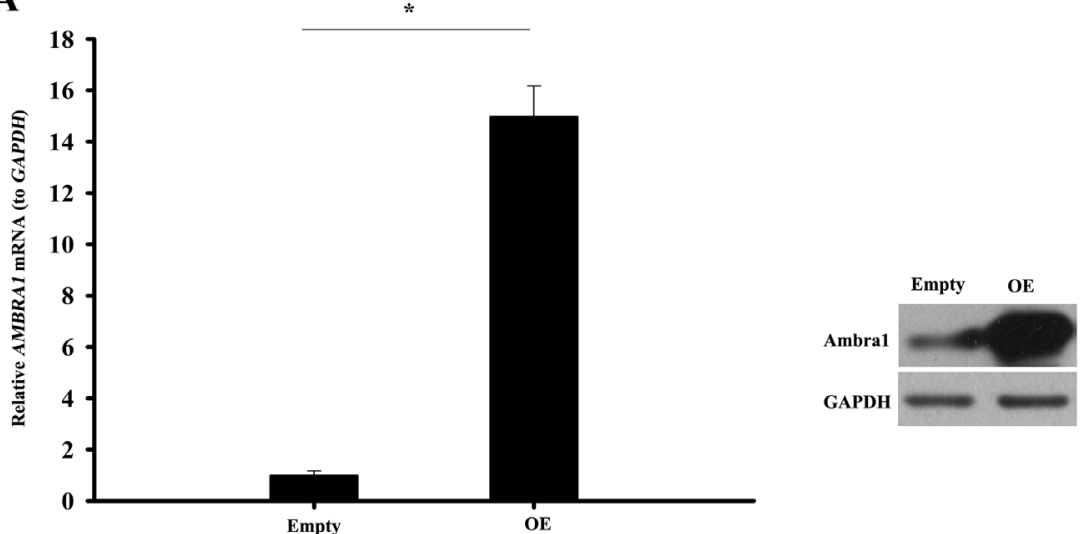

\section{B}
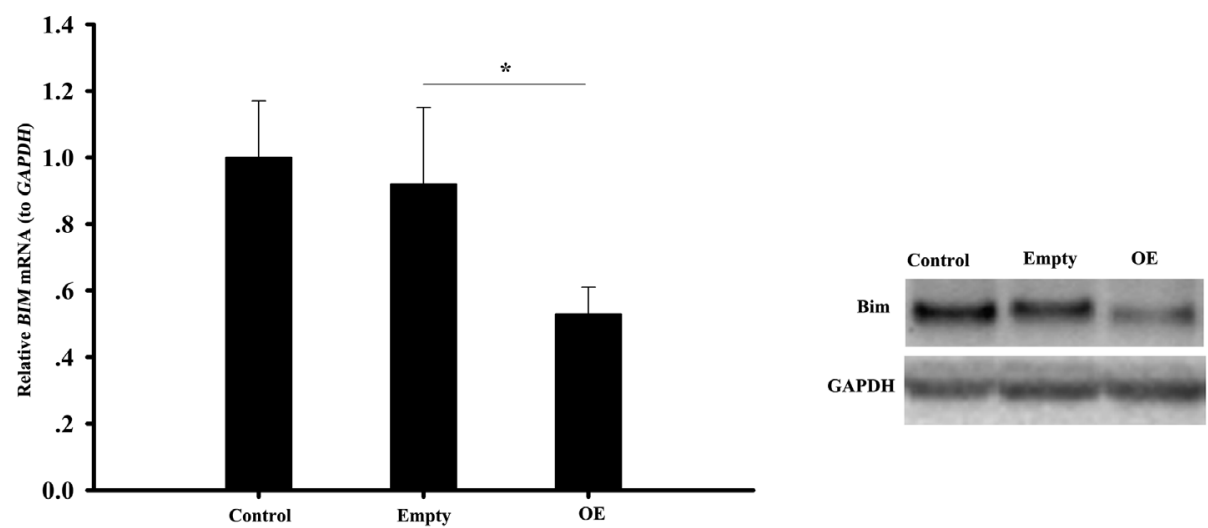

Supplementary Figure 1. Overexpression of Ambra1 inhibited Bim expression in MDA-MB-231 cells. A) MDA-MB-231 cells were treated by the lentiviral vector-AMBRA1 transfected with full-length human $A M B R A 1 \mathrm{cDNA}$ (abbreviated as $\mathrm{OE}$ ) and an empty vector (Empty, as a control) for $72 \mathrm{~h}$; and then the mRNA of AMBRA1 was tested by qRT-PCR, and the protein of Ambral was detected by western blotting. B) Cells were incubated with OE or Empty for $72 \mathrm{~h}$; the mRNA and protein of Bim were tested by qRT-PCR and western blotting respectively. All the data (means \pm SD) are from three independent experiments $\left({ }^{*} \mathbf{p}<0.05\right)$. 